Dokuz Eylül Üniversitesi-Mühendislik Fakültesi

Fen ve Mühendislik Dergisi

Cilt 20, Sayı 59, Mayıs, 2018
Dokuz Eylul University-Faculty of Engineering Journal of Science and Engineering Volume 20, Issue 59, May, 2018

DOI: $10.21205 /$ deufmd. 2018205934

\title{
Kablosuz Algılayıcı Ağlarında Alıcı-Vericilerin Oransal-İntegral Denetleyiciler ile Görev Döngüsü
}

\author{
Kasım Sinan YILDIRIM*1 \\ ${ }^{1}$ Ege Üniversitesi, Mühendislik Fakültesi, Bilgisayar Mühendisliği Bölümü, \\ 35100, Bornova, İzmir
}

(Alınıș / Received: 27.03.2017, Kabul / Accepted: 25.12.2017, Online Yayınlanma / Published Online: 15.05.2018)

\begin{abstract}
Anahtar Kelimeler Özet: Algılayıcı düğümlerinin enerji tüketimi, görev çevrimi Kablosuz Algılayıcı Ağları, Görev Çevrimi, Oransal-İntegral Denetleyici tekniği olarak adlandırılan alıcı-vericilerinin etkinleștirilip kapatılmasıyla oldukça düşürülebilir. Ancak görev çevriminin uygulanması kolay değildir çünkü düğümler alıcı vericilerini etkinleştirmek için verinin ne zaman geleceğini önceden bilmek zorundadırlar. Bu makalede, düğümler arasında sabit bir devirde haberleșme olduğu varsayılarak, düğümler arasında açık bir saat eşzamanlaması gerektirmeyen verimli bir görev çevrimi tekniği tanıtılmaktadır. Daha iyi ifade edilecek olunursa, bu makale güncel literatürde oransal-integral tabanlı görev çevrimini tanıtan bilgimiz dahilindeki ilk makaledir. Önerilen yöntemin en önemli avantajı hesaplama ve bellek yükü açısından oldukça hafif olmasıdır. Önerilen yöntem derinlemesine bir matematiksel analizle desteklenmiş ve analizlerin doğruluğu benzetimler aracilığlyla gösterilmiștir.
\end{abstract}

\section{Duty Cycling of Transceivers in Wireless Sensor Networks Using Proportional-Integral Controllers}

\begin{tabular}{ll}
\hline Keywords & Abstract: The energy consumption of the sensor nodes can be \\
Wireless Sensor & reduced considerably by turning on and off their transceivers, the \\
Networks, Duty & so called duty-cycling. However, the difficulty of duty-cycling is \\
Cycling, & that nodes should know beforehand when data is coming and then \\
Proportional- & they need to switch on their transceivers to receive the incoming \\
Integral & data. In this article, we assume a periodic communication between \\
Controller & two sensor nodes at a fixed frequency and introduce an efficient \\
& duty-cycling technique that does not require explicit time \\
& synchronization between the nodes. More precisely, up to our \\
& knowledge, this is the first article in the current literature \\
& proposing a proportional-integral controller-based duty-cycling \\
& mechanism. A desirable property of this technique is that it is \\
& lightweight in terms of computation and memory overhead. We \\
& support our article by providing an extensive mathematical \\
& analysis of our technique and show the correctness of our analysis \\
& through simulations.
\end{tabular}

Sorumlu yazar: Kasım Sinan Yıldırım email: sinan.yildirim@ege.edu.tr 


\section{Giriş}

Dağıtık bilgisayar sistemleri, sistem genelindeki bir veya birden çok görevi işbirliği içinde yerine getirebilmek için birbirleri ile haberleșen ve eylemlerini eşgüdümleyen, düğüm adı verilen bilgi ișleme yeteneğine sahip donanımlardan oluşmaktadırlar [1]. Dügüumlerin her birinin kendi özel saat donanımı ve dolayısıyla kendisi için özel bir zaman algısı; başka bir deyişle yerel saati vardır. Her bir yerel saat farklı hızda ilerlediği için, düğümler aynı anda çalışmaya başlasalar bile saatler zaman içinde birbirlerinden sapacak (drift) ve sistemdeki tüm düğümlerin farklı bir zaman algisı olacaktır. Ancak, düğümlerin sistem genelindeki görevleri doğru ve verimli bir şekilde yerine getirebilmeleri, genellikle aralarında ortak; yani genel bir zaman kavramının olmasını gerektirmektedir. Dağıtık sistemlerde ortak bir zaman algısının oluşturulması için, düğümler kendi iletișim kapsama alanındaki diğer düğümlerle haberleșerek bir saat eşzamanlama algoritması [2] çalıştırmalı ve sistemdeki genel saat kavramını temsil eden bir mantıksal saat değeri hesaplamalıdırlar. Dağıtık saat eşzamanlama algoritmalarının ana amacı sistemdeki tüm düğümlerin mantıksal saatleri arasındaki farkı, diğer bir deyişle eşzamanlama hatalarını, en aza indirmektir. Ne yazık ki hiçbir saat eşzamanlama algoritması dügüumlerin birbirleri ile iletişimi süresince meydana gelen belirsiz gecikmeler ve saat sapmaları nedeniyle mükemmel bir eşzamanlama sağlayamaz [3].

Buna ek olarak, düğümlerin bazı işlemleri işbirliği ile yerine getirebilmesi için her zaman saat eşzamanlaması algoritması işletmelerine gerek yoktur. Örneğin, bir düğüm kendi kapsama alanı içerisindeki diğer bir düğümden sabit bir devirde veri allyorsa, sadece kendi yerel saatini kullanarak bir sonraki verinin ne zaman gelebileceğini tahmin edebilir. Dolayısıyla, devirsel olarak meydana gelen olayların zamanını tahmin edebilmek için açlk bir saat eşzamanlamasına her zaman gerek kalmayabilir [4]. Bu sayede, saat eşzamanlamasının getireceği iletişim ve hesaplama yükü ortadan kalkmıș olmaktadır.

Günümüzde, dağıtık bilgisayar sistemlerinin pratikteki özel bir kolu olan kablosuz algılayıcı ağları (KAA) araştırmacıların ilgisini yoğun bir şekilde çekmektedir. Kabaca bir mikrodenetleyici, değişik algılayıcılar ve alıcl-verici (transceiver) donanımından oluşan KAA düğümleri, fiziksel çevrenin gözlemlenmesi, konum belirleme ve nesne tespiti gibi dağıtık uygulamaların geliştirilmesi için kullanılmaktadırlar [5]. KAA dügümleri, güçlerini pillerden aldıkları için, işlemlerini kısıtlı ve sonlu enerjiyi göz önüne alarak gerçekleştirmelidirler. Dolayısıyla, algılayıcı düğümleri, işlemlerini gerçekleştirirken bir görev çevrimi (dutycycle) uygulamalıdırlar [6].

Görev çevriminin sağlanabilmesi için, dügümlerin mikrodenetleyicilerinin çeşitli düşük-güç çalışma kiplerine (lowpower operation mode) sahip olmaları geremektedir. Örneğin TI MSP430 [7] beș adet düşük-güç kipine sahiptir. En düşük güç tüketim kipi olan LPM 4'te mikrodenetleyici ve tüm yan aygitlar kapalı tutulmakta, sistem bir dışsal kesme (external interrupt) tarafindan uyanacak şekilde bekletilmektedir. LPM 3 ise $u y k u$ kipi olarak adlandırılmaktadır ve bu kipte sadece dişsal $32 \mathrm{KHz}$ salınım üreteci (oscillator) ve bu salınım üretecini kullanan zamanlayıcılar (timer) etkindir. Mikrodenetleyicilere ek olarak, düğümlerin alıcı-vericileri de açılıp kapatılma özelliğine sahiptirler. Alıcıvericiler, algılayıcı donanımının en fazla enerji tüketen elemanıdır ve mümkün 
olduğunca kapalı tutulmalıdırlar. Tablo 1, olduğunca uyku kipinde tutmalı ve ancak Telos ve MICAz platformlarındaki gerektiğinde etkin hale getirerek mikrodenetleyici ve alıcı-vericilerin işlemleri hızlı bir şekilde yapıp tekrar enerji gereksinimlerini özetlemektedir. uyku kipine geçirmelidir. Benzer şekilde, Dikkat edilecek olursa, alıcı-verici ve alıcl-vericiler de ancak veri gönderimi ve mikrodenetleyicilerin uykudan alımı zamanlarında etkin hale getirilmeli uyanmaları anlık olmamakta, etkin hale ve gereksiz durumlarda kapatılmalıdır. gelmeleri belirli bir sürenin geçmesini Görev çevrimi yöntemleri, gerektirmektedir.

Sonuç olarak, algılayıcı düğümleri vericilerin ne zaman etkin hale getirilip mikrodenetleyicilerini mümkün ne zaman kapatılacağını belirlerler.

Tablo 1. Telos ve MICAz platformlarına ilişkin enerji tüketimi ile ilgili sistem parametreleri. Bu değerler [8] çalışmasında yer alan Şekil 6'dan alınmıştır.

\begin{tabular}{|l|l|l|}
\hline İșlem & Telos & MICAz \\
\hline MCU (Mikrodenetleyici) & TI MSP430 & Atmel Atmega 128 \\
Alıcl-Verici & Chipcon CC2420 & Chipcon CC2420 \\
\hline Minimum Voltaj & $1.8 \mathrm{~V}$ & $2.7 \mathrm{~V}$ \\
\hline Uyku Kipi & $5.1 \mu \mathrm{A}$ & $27.0 \mu \mathrm{A}$ \\
MCU Boș & $54.5 \mu \mathrm{A}$ & $3.2 \mathrm{~mA}$ \\
MCU Etkin & $1.8 \mathrm{~mA}$ & $8.0 \mathrm{~mA}$ \\
MCU + Alıcl-Verici (Alım) & $21.8 \mathrm{~mA}$ & $23.3 \mathrm{~mA}$ \\
MCU + Alıcl-Verici (Gönderim) & $19.5 \mathrm{~mA}$ & $21.0 \mathrm{~mA}$ \\
\hline
\end{tabular}

\subsection{Katkılar}

Daha önce de vurgulandığı gibi, görev çevrimi ile alıcl-vericilerin etkinleştirilebilmesi ve uyutulabilmesi için, her bir algılayıcı düğümü diğer düğ̈̈mlerden gönderilecek verinin alım zamanını kendi saatini kullanarak tahmin etmeli, bu zamandan biraz önce alıcıvericisini açmalı ve veri alındıktan sonra kapatmalıdır. $\mathrm{Bu}$ makalede, güncel literatürde ilk defa, bu işlevsellik oransalintegral denetleyici (proportionalintegral controller) prensibinden esinlenerek, açı bir saat eşzamanlamasına ihtiyaç duyulmadan sağlanmaktadır. Oransal-integral denetleyiciler son yıllarda verimlilikleri nedeniyle KAA çalışmalarında öne çıkmaktadırlar. Özellikle saat eşzamanlama alanında yapılan $[9,16,17]$ çalışmaları bu basit prensibin enerji ve kaynak kısıtlarına sahip dügümler için çok uygun olduğunu ortaya koymuştur. Doğrusal bağlanım (linear regression) gibi yöntemler KAA'larda sıkça kullanılmasına rağmen [10], birçok hesaplama adımı içermeleri ve hatırı sayılır bir bellek ihtiyacının olması nedeniyle oransal-integral denetleyicilerle kıyaslandığında oldukça fazla bir hesaplama ve bellek yükü getirmektedirler.

Bu çalışmada, KAA düğümlerinin sabit bir devirde birbirlerine veri gönderdikleri varsayılmaktadır. $\mathrm{Bu}$ varsayım kullanarak, açı bir saat eşzamanlamasına ihtiyaç duymayan ve çok basit işlem adımlarına sahip, yükte hafif bir görev çevrimi yöntemi önerilmektedir. $\mathrm{Bu}$ makale güncel literatüre aşağıdaki katkıları sunmaktadır:

- Oransal-integral denetçiler ve kontrol tabanlı yöntemler daha önce saat senkronizasyonu için kullanılmışlardır $\quad[9,16,17,18]$. Ancak bu makale ile literatürde ilk defa alıcı-vericilerin görev çevrimi için oransal-integral denetçi tabanlı bir yöntem 
geliştirilmiştir. Geliştirilen iletilebilecek/alınacak veri miktarını yöntem saat eşzamanlamasına azaltabilir. Dügümlerin alıcı-verici ihtiyaç duymamaktadır.

- Önerilen yöntem kaynak gereksinimleri açısından tartışılmakta ve avantajları somut bir şekilde ifade edilmektedir.

donanımını denetlemek ve etkinlik/uyku devirlerini eşgüdümlemek Ortam Erişimi Katmanı-OEK (Medium Access Layer) sorumluluğundadır.

OEK protokolleri B-MAC [11]

- $\mathrm{Bu}$ yöntemin, iki düğüm göz önüne alınarak ve üniform devingen bir saat sapması modeli kullanılarak teorik analizi literatürde ilk defa sunulmaktadır.

- Teorik sonuçlar, benzetimler yardımıyla doğrulanarak, önerilen yöntemin başarımı hakkında çıkarımlar yapılmıştır.

- Önerilen yöntemin pratikte başarı ile uygulanabileceği, gerçek bir KAA ortamında gerçekleştirilerek ve sonuçlar sunularak gösterilmiştir.

2. İlgili Çalışmalar: Kaa'larda AlıcıVericilerin Görev Çevrimi

Algılayıcı düğümlerinin alıcı-vericilerinin (iletişim donanımının) verimsiz kullanımı, Tablo 1'den de görüleceği gibi enerji israfına neden olur. Ağda hiçbir iletişim eylemi yoksa ve dügümlerin alıcıvericileri uyku durumuna geçirilmediyse, algılayıcı düğümler diğer dügümlerden gelebilecek olası paketleri her an alabilmek için iletişim ortamını boşa dinlemekte (idle listening) ve gereksiz yere enerji harcamaktadırlar. Enerji tüketimini azaltmak ve ağın yaşam süresini uzatmak için algılayıcı düğ̈̈mleri alıcl-vericilerini kapatıp açarak bir görev çevrimi sürecini gerçekleștirmek zorundadırlar. Düğümlerin görev çevrimini gerçekleştirebilmeleri için diğer dügümlerden ne zaman veri gelebileceğini tahmin etmeleri ve veri gelmeden hemen önce veriyi almak için alıcı-vericilerini etkin hale getirmeleri gerekmektedirler. Tahminleme hataları protokolündeki gibi kanal erişiminin rastgele olması ilkesiyle çalışabilir. Rastgele kanal erişimine dayalı OEK protokolleri ile görev çevrimi, etkinlik/uyku devrinin ne zaman gerçekleşeceği konusunda herhangi bir ön bilgi gerektirmez. Dolayısıyla, dügümlerin eşgüdümlü çalışmasına ihtiyaç yoktur. Her düğüm alıcl-vericisini diğer düğümlerden bağımsız olarak belirli bir devirde etkinleștirir ve ortamda iletişim olup olmadığını denetler. Ancak, gönderici düğümler alıcı dügümlerin uyanmasını ve gönderilen paketi almalarını garantilemek için uzun bir öncül bit dizisi (preamble) göndermelidir. Bu sayede, devirsel olarak alıcı-vericilerini etkinleștiren alıcı düğümler bu öncülü algılayacak ve alıcıvericilerini paketi almak için açı tutacaklardır. Alıcı düğümleri uyandırabilmek için uzun bir öncül paket gönderme yöntemine Düşük Güç Dinleme (Low-Power Listening) denmektedir.

Bunun dışında, S-MAC [12] gibi dilimli erişim (slotted access) OEK protokolleri, alıcı-vericilerin aynı anda etkinleștirilip uyutulması için algılayıcı düğümleri arasında eşgüdümlemeye ihtiyaç duyarlar. Düğümler her bir dilimin başında uyanır, iletişim kanalını denetleyerek ya paket gönderir veya o an gönderilmekte olan paketi alırlar. Alım veya gönderim işlemi sonunda ise alıcıvericilerini tekrardan uyku durumuna getirirler. Cerçeve (frame) tabanlı OEK protokolleri, örneğin zaman bölüşümlü çoklu erişim-ZBÇE (TDMA) tabanlı LMAC [13] protokolü gibi, çekişmeleri (contention) ve paket çarpışmalarını (collision) engellemek için gönderen ve 
alıcılara zamanlanmış dilimler Algılayıcı dügümleri saatlerini atamaktadırlar. ZBÇE tabanlı OEK eşzamanlamak için, kendilerinin iletişim protokollerinde, her bir düğüme veri kapsamı içerisinde yer alan komşu göndermek veya almak için devingen düğümlerin saat/zaman bilgilerini veya durağan zaman dilimleri atanır.

Eğer düğümler bu zaman dilimlerini biliyorlarsa ve ortak bir zaman kavramina sahiplerse, bu zaman dilimlerinin başında alıcı-vericilerini etkinleștirerek gelen paketleri alabilirler veya paket gönderebilirler. Algılayıcı düğ̈̈mlerinin yerel saatleri alıcıvericilerin eşgüdümlü etkinleștirilme/uyutulma eylemleri sağlamak için tek başına yeterli değildir. Frekans hataları nedeniyle, yerel saatler sık sık birbirinden sapar ve dolayısıyla yerel saatler yalnızca ilgili düğüme özel bir yerel saat kavramı sağlayabilir.

öğrenmeli ve dolayısıyla onlarla devirsel iletişim kurmalıdırlar. Saat eşzamanlanması olarak adlandırılan genel bir zaman kavramının oluşturulması, alıcı-vericilerin eşgüdümlü bir șekilde uyutulup etkinleștirilmesi ve dolayısıyla enerjiden tasarruf etmek için önemli bir yapı taşıdır. Literatürde KAA'larda saat eşzamanlaması sağlamak için önerilmiş ve saat eşzamanlama hatasını en az sayıda veri iletişimi yaparak azaltmak amacıyla tasarlanmış çeşitli protokoller yer almaktadır $[9,10,14,15,16,17,18,19,20]$.

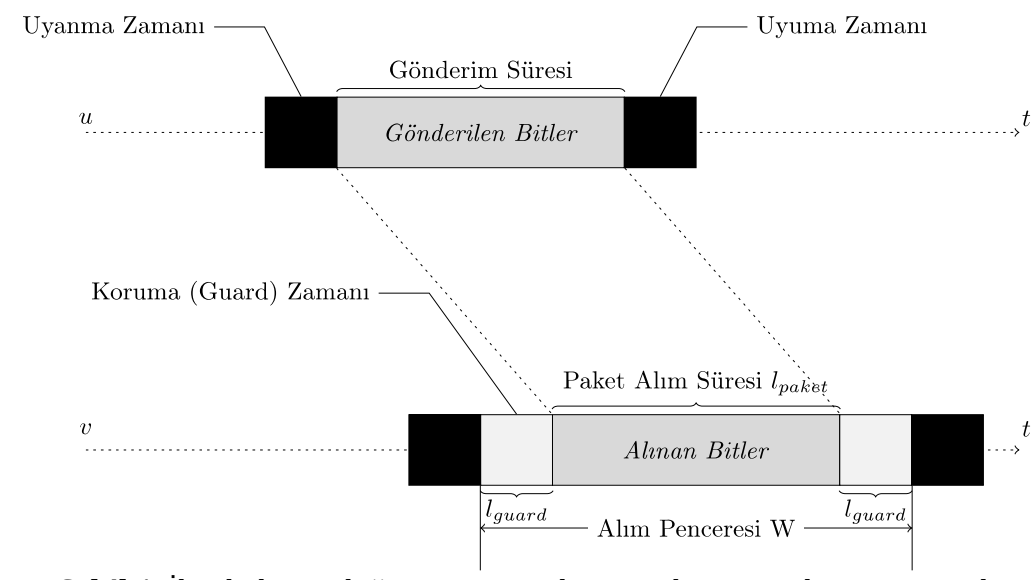

Şekil 1. İki algılayıcı dügümü arası paket gönderim ve alımının temsili.

Bir diğer yaklaşımda ise, eğer düğümlerin paket gönderme yani iletişim periyodu sabit ise, algilayıcı düğümleri komşularının veriyi ne zaman göndereceklerini saat eşzamanlamasina gerek kalmadan öğrenebilirler. Verimli görev çevrimi için, düğümler verilerin ne zaman geleceğini tahmin etmeli ve daha sonra verileri almak için alıcı-vericilerini etkinleștirmelidirler. $\mathrm{Bu}$ yaklașımda, herhangi bir alıcı düğümün veriyi almak için alıcl-vericisini açık tutma süresi, başka bir deyişle paket alma penceresi $W$ (receiving window), saat tahminleme doğruluğuna bağlıdır. Şekil 1'de birbirleri ile iletişimde bulunan iki düğüm gösterilmektedir. $\quad v \quad$ düğümü $u$ dügümünden gelecek paketi tahmin ettiği zamandan koruma zamanı (guard time) kadar önce alıcl-vericisini etkinleștirmelidir. $\mathrm{Bu}$ sayede, tahminleme hatalarını telafi etmiş olur. Dolayısıyla, W değerinin büyüklüğü alınan paketin alım süresinin uzunluğunu ifade eden $l_{\text {paket }}$ değerine ek olarak tahminleme hatasının varyansını ifade eden $l_{\text {guard }}$ değerine de bağlıdır. 


\section{Sistem Modeli ve Tanımlar}

Bu çalıșmada, iletișim ağındaki birbirine komşu iki düğümü göz önüne alacağız ve bu düğümleri u ve v ile temsil edeceğiz. Ağdaki bu iki düğümün sadece okunabilir ve değeri değiștirilemez saat donanımlarına sahip olduklarını varsayacağız. Buna ek olarak, saatlerin salınım üreteçlerinin (oscillator) $\mathrm{f}^{*}$ nominal frekansında titreşme özelliğine sahip olduklarını varsayacağız. Sıcaklık

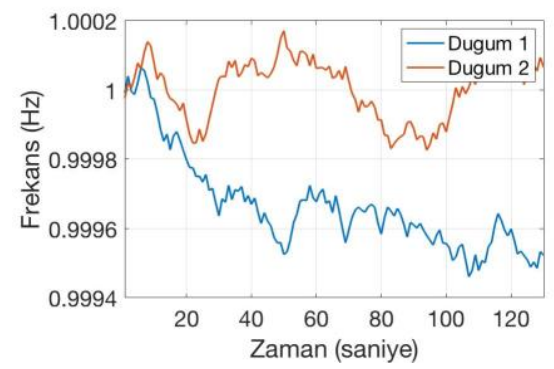

gibi çevresel etkenler ve enerji seviyesi gibi dügüm donanımına özgü etkenler nedeniyle, dügümlerin saat frekansları $f_{u}$ ve $f_{v}$ istenilen $f^{*}$ değerinden ve dolayısıyla birbirlerinden sapmalar göstermektedir. Tanım olarak $u$ düğümünün $t>t_{0}$ anındaki yerel saati

$$
\mathrm{t}_{\mathrm{u}}(\mathrm{t}) \triangleq \mathrm{t}_{\mathrm{u}}\left(\mathrm{t}_{0}\right)+\int_{\mathrm{t}_{0}}^{\mathrm{t}} \mathrm{f}_{\mathrm{u}}(\sigma) \mathrm{d} \sigma
$$

ile ifade edilmektedir. Burada $\mathrm{f}_{\mathrm{u}}(\sigma)$ düğümün $\sigma$ anındaki saat frekansıdır.

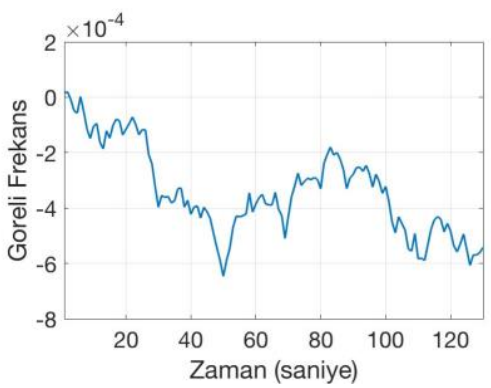

Şekil 2. İki düğümün anlık (solda) ve göreli (sağda) saat frekansı.

Şekil 2'de iki düğümün temsili olarak saat frekansları ve bu iki frekans değerinin birbirine göreli değeri olan $\mathrm{f}_{\mathrm{v}}^{\mathrm{u}}=\frac{\mathrm{f}_{\mathrm{u}}}{\mathrm{f}_{\mathrm{v}}}-1 \quad$ değeri gösterilmiştir. $\mathrm{Bu}$ çalışmada saatlerin devingen sapmalarını, aşağıda gösterildiği gibi bir rastgele süreç olarak aşağıdaki gibi modelleyeceğiz:

$$
\mathrm{f}_{\mathrm{v}}^{\mathrm{u}}\left(\mathrm{t}_{0}+\delta\right) \triangleq \mathrm{f}_{\mathrm{v}}^{\mathrm{u}}\left(\mathrm{t}_{0}\right)+\eta\left(\mathrm{t}_{0}+\delta\right)
$$

Burada $\eta(t)$ göreli saat frekansındaki $t$ anındaki anlık değișimi ifade etmektedir. İlerleyen bölümlerdeki hesaplamaların basitliği açısından, $\eta(t)$ değerini $[-\varepsilon, \varepsilon]$ aralığında bir uniform şans değişkeni olarak varsayacağız. Dolayısıyla, $\eta(\mathrm{t})$ parametresi 0 ortalamaya ve $\sigma_{\eta}^{2}=\frac{\varepsilon^{2}}{3}$ varyansına sahip bir şans değişkenidir. $\overline{\mathrm{f}}_{\mathrm{v}}^{\mathrm{u}}\left(\mathrm{t}_{0}, \mathrm{t}_{0}+\delta\right), \quad \delta \quad$ uzunluğuna sahip $\left[\mathrm{t}_{0}, \mathrm{t}_{0}+\delta\right]$ zaman aralığındaki ortalama göreli saat frekansı değerini temsil etsin. $\mathrm{f}_{\mathrm{v}}^{\mathrm{u}}$ ve $\overline{\mathrm{f}}_{\mathrm{v}}^{\mathrm{u}}$ arasındaki ilișkiyi așağıdaki gibi ifade edebiliriz:

$$
\begin{aligned}
\bar{f}_{v}^{u}\left(t_{0}, t_{0}+\delta\right) & \triangleq \frac{1}{\delta} \int_{t_{0}}^{t_{0}+\delta} f_{v}^{u}(t) d t \\
& =f_{v}^{u}\left(t_{0}\right)+\frac{1}{\delta} \int_{t_{0}}^{t_{0}+\delta} \eta(t) d t
\end{aligned}
$$

İlerleyen bölümlerdeki matematiksel hesaplamalarımızın açık ve basit bir şekilde ifade edilebilmesi için, dügümler arasındaki iletişim süresince paketlerin kaybolmadığını varsayacağız. Bir düğüün paket göndermeye başlamasından alıcı düğümün o paketi almasına kadar geçen süreye iletişim gecikmesi adını vereceğiz. Merkezi limit teoremi ve deneysel gözlemler sonucunda [14], iletişim gecikmelerini d ile gösterip 0 ortalamaya ve $\sigma_{\mathrm{d}}^{2}$ varyansa sahip bir normal şans değişkeni olarak modelleyeceğiz.

Özetle, șu ana kadarki tanımlarımız göz önüne alınacak olursa, sistemdeki temel rastgeleliği yaratan parametreler saatlerin devingen sapmalarını ifade 
eden $\eta$ ve mesaj gecikmelerini ifade eden bir iletişim senaryosunu göstermektedir. d şans değişkenleridir.

Devirsel iletişimin sonucu olarak, v düğ̈mü bir sonraki paketi alıncaya

\section{Alıcı-Vericilerin Oransal-İntegral} Denetleyiciler ile Görev Çevrimi

$\mathrm{Bu}$ bölümde, $\quad \mathrm{v}$ düğ̈̈münün $\mathrm{u}$ dügümünden her $\tau$ saniyede bir paket aldığı bir gönderim-alım senaryosu üzerine odaklanacağız [15]. Şekil 3 örnek kadar alıcı-verici donanımını uyku durumuna getirerek enerji kazancı sağlamakta, sonraki paketin alınacağı tahmini zamanda ise alıcı-vericileri etkinleștirerek paketin doğru bir şekilde alınmasını garanti altına almaktadır.

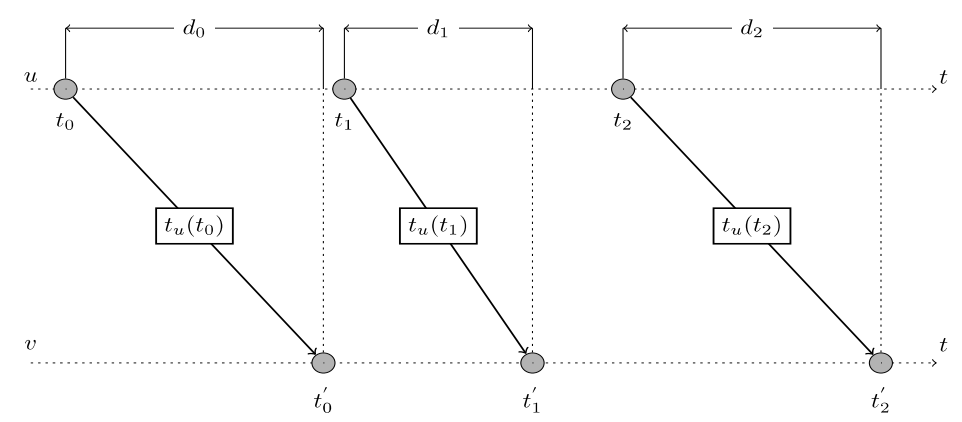

Şekil 3. Düğümler arasındaki paket gönderim-alım sürecinin temsili gösterimi.

\subsection{Sonraki Paket Alım Zamanının} Tahmini

İletişim devri olan $\tau$ değerinin sabit ve tüm düğümler tarafından bilindiğini varsayalım. Şekil 3'te gösterildiği gibi, v dügümü $\mathrm{u}$ dügümünden tam olarak $\mathrm{t}_{2}^{\prime}$ anında alacağı paketin alınma zamanını, kendi saatini kullanarak bir önceki paketi aldığı $t_{1}^{\prime}$ anında aşağıdaki gibi tahmin edebilmektedir:

$$
\hat{\mathrm{t}}_{\mathrm{v}}\left(\mathrm{t}_{2}^{\prime}\right)=\mathrm{t}_{\mathrm{v}}\left(\mathrm{t}_{1}^{\prime}\right)+\tau\left(1+\hat{\mathrm{f}}_{\mathrm{v}}^{\mathrm{u}}\left(\mathrm{t}_{1}^{\prime}\right)\right)
$$

Burada $\hat{\mathrm{f}}_{\mathrm{v}}^{\mathrm{u}}\left(\mathrm{t}_{1}^{\prime}\right)$ tahmini göreli saat frekansının $t_{1}^{\prime}$ anındaki değerini ifade etmektedir. Dolayısıyla, paketin alınacağı anda $\mathrm{v}$ düğümünün saatinin değeri $t_{v}\left(t_{2}^{\prime}\right)$ ile bu paketin tahmini alım anındaki saat değeri $\hat{t}_{v}\left(t_{2}^{\prime}\right)$ arasındaki fark tahminleme hatasıdır ve aşağıdaki şekilde ifade edilmektedir:

$$
\begin{aligned}
\tilde{\mathrm{t}}_{\mathrm{v}}\left(\mathrm{t}_{2}^{\prime}\right) & =\mathrm{t}_{\mathrm{v}}\left(\mathrm{t}_{2}^{\prime}\right)-\hat{\mathrm{t}}_{\mathrm{v}}\left(\mathrm{t}_{2}^{\prime}\right) \\
& =\mathrm{t}_{\mathrm{v}}\left(\mathrm{t}_{2}^{\prime}\right)-\mathrm{t}_{\mathrm{v}}\left(\mathrm{t}_{1}^{\prime}\right)-\tau\left(1+\hat{\mathrm{f}}_{\mathrm{v}}^{\mathrm{u}}\left(\mathrm{t}_{1}^{\prime}\right)\right)
\end{aligned}
$$

Açık bir şekilde, buradaki ana amaç paketin geliş zamanını doğru tahminlemek, dolayısıyla alıcı-vericiyi zamanında etkinleștirerek gelen paketin doğru bir şekilde alınmasını sağlamaktır. Doğru tahminlemek, bir başka ifadeyle tahminleme hatası olan $\tilde{t}_{v}\left(t_{2}^{\prime}\right)$ değerini en aza indirgemektir. Görüleceği gibi yukarıdaki ifadede tahminleme hatasını etkileyen temel eleman göreli tahmini saat frekansı değeri olan $\hat{\mathrm{f}}_{\mathrm{v}}^{\mathrm{u}}\left(\mathrm{t}_{1}^{\prime}\right)$ değeridir. Dolayısıyla, bu değer ne kadar iyi tahminlenirse, tahmini paket alım zamanı o ölçüde iyi tahminlenecek ve paket alımı garanti altına alınacaktır.

Așağıdaki ifadenin doğru olduğunu varsayalım:

$$
\begin{aligned}
t_{v}\left(t_{2}^{\prime}\right)-t_{v}\left(t_{1}^{\prime}\right) & \simeq t_{v}\left(t_{2}\right)-t_{v}\left(t_{1}\right)+d_{2} \\
& -d_{1} .
\end{aligned}
$$

Burada $d_{2}$ ve $d_{1}$ iletişim süresince meydana gelen gecikmeleri ifade etmektedir. $\quad t_{v}\left(t_{2}\right)-t_{v}\left(t_{1}\right)=\tau(1+$ $\left.\overline{\mathrm{f}}_{\mathrm{v}}^{\mathrm{u}}\left(\mathrm{t}_{1}, \mathrm{t}_{2}\right)\right)$ geçerli olduğu için: 
$\tilde{\mathrm{t}}_{\mathrm{v}}\left(\mathrm{t}_{2}^{\prime}\right)=\tau\left(\overline{\mathrm{f}}_{\mathrm{v}}^{\mathrm{u}}\left(\mathrm{t}_{1}, \mathrm{t}_{2}\right)-\hat{\mathrm{f}}_{\mathrm{v}}^{\mathrm{u}}\left(\mathrm{t}_{1}^{\prime}\right)\right)+\mathrm{d}_{2}-\mathrm{d}_{1} \quad \begin{aligned} & \text { düğümmünden bir paket aldığı̆nda, tahmini } \\ & \text { göreli saat frekansını güncellemesi için }\end{aligned}$ $=\tau \tilde{\mathrm{f}}_{\mathrm{v}}^{\mathrm{u}}\left(\mathrm{t}_{1}\right)+\frac{\tau}{\mathrm{t}_{2}-\mathrm{t}_{1}} \int_{\mathrm{t}_{1}}^{\mathrm{t}_{2}} \eta(\mathrm{t}) \mathrm{dt}$ $+\mathrm{d}_{2}-\mathrm{d}_{1}$

elde edilmektedir. Burada $\tilde{\mathrm{f}}_{\mathrm{v}}^{\mathrm{u}}\left(\mathrm{t}_{1}\right)$ saat frekansı tahminleme hatasıdır ve aşağıdaki gibi tanımlanmaktadır:

$$
\tilde{\mathrm{f}}_{\mathrm{v}}^{\mathrm{u}}\left(\mathrm{t}_{1}\right) \triangleq \mathrm{f}_{\mathrm{v}}^{\mathrm{u}}\left(\mathrm{t}_{1}^{\prime}\right)-\hat{\mathrm{f}}_{\mathrm{v}}^{\mathrm{u}}\left(\mathrm{t}_{1}^{\prime}\right)
$$

\subsection{Göreli Saat Frekansının Oransal- İntegral Denetçi ile Tahminlenmesi}

$\mathrm{Bu} \quad$ makalede, oransal-integral denetçilerle saat eşzamanlaması çalışmasından [9] esinlenerek ve [16] çalışmasını taban alarak, v düğümünün u aşağıdaki algoritmayı öneriyoruz:

$$
\hat{\mathrm{f}}_{\mathrm{v}}^{\mathrm{u}}\left(\mathrm{t}_{2}^{\prime}\right)=\hat{\mathrm{f}}_{\mathrm{v}}^{\mathrm{u}}\left(\mathrm{t}_{1}^{\prime}\right)-\alpha \tilde{\mathrm{t}}_{\mathrm{v}}\left(\mathrm{t}_{1}^{\prime}\right)
$$

Bu tahmin güncelleme algoritmasında $\alpha$ değeri integral kazancı olarak adlandırılmakta ve algoritmanın başarımında önemli bir parametre olarak etki göstermektedir. Bu gerçeği ilerleyen adımlarda daha da açık bir şekilde ifade edeceğiz. Dolayısıyla, yukarıdaki algoritma bir oransal-integral denetleyicidir ve her güncelleme adımında döngülü (iterative) bir şekilde tahmin hatasını sıfır değerine yaklaştırmaktadır. Bunu her döngüde tahmini göreli saat frekansı hatasını sıfır değerine yaklaştırarak başarmaktadır.

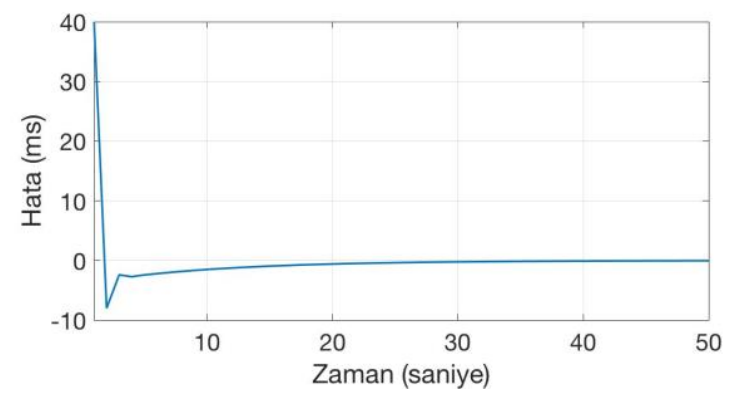

Şekil 4. Tahminleme hatasını için benzetimler.

Önerdiğimiz oransal-integral denetleyici tabanlı algoritmayı MATLAB ortamında geliştirdik ve benzetimler sonucunda elde edilen hata değerlerini Şekil 4'te göstermekteyiz. Tahminleme hatası her güncelleme adımında iyileşerek sonuçta sıfır değerine yakınsayacaktır. Benzetimlerde $\alpha=10^{-6}$ ve $\mathrm{f}^{*}=32768$ olarak seçilmiştir.

Oransal-integral denetleyici tabanlı görev çevrimi, görüldüğü gibi geliştirilmesi oldukça basit bir yöntem olması nedeniyle, KAA ağları için tam manasıyla uygundur. Öncelikle ifade etmek gerekirse, her $v$ düğümü sadece $\hat{\mathrm{f}}_{\mathrm{v}}^{\mathrm{u}}$ değerini güncellemekte, ve bu güncelleme işlemi sadece 1 çarpma ve 1 çıkarma işlemiyle gerçekleştirilmektedir. Dolayısıyla, doğrusal bağlanım kullanan diğer yöntemlere kıyasla [10], hesaplama ve bellek gereksinimleri açısından oldukça hafiftir.

\section{5. Önerilen Yöntemin Teorik Analizi}

$\mathrm{Bu}$ bölümde, önerilen yöntemin teorik analizini gerçekleştirilmektedir. Öncelikle, yöntemin tahminleme hatasını beklenende sıfır değerine varacağ Teorem 1 ile ispatlanacaktır. Teorem 2 ile yöntemin asimptotik varyansını 
gösterilecektir. $\mathrm{Bu}$ değer, döngüsel yöntemin döngü adımı sonsuza giderken, sistemdeki rastgelelikten dolayı oluşan tahminleme hatasının sinırlarını ifade edecektir. Dolayısıyla, önerilen yöntemin hatasının analitik ifadesi, hatanın sistemdeki hangi parametrelere bağlı olduğunu ve bunlardan nasıl etkilendiğini gösterecektir.

Teorem 1: Oransal-integral denetçilerle görev çevrimi uygulandığında, beklenende bütün paketlerin alınma zamanı doğru tahmin edilecektir.

İspat: Hesaplama adımlarını basitleştirebilmek için aşağıdaki gösterimleri kullanacağı:

$$
\begin{aligned}
\mathrm{a}(h) & =\frac{\tau}{t_{h+1}-t_{h}} \int_{t_{h}}^{t_{h+1}-t_{h}} \eta(t) d t, \\
\mathrm{~b}(h) & =d_{h+1}-d_{h}, \\
\Delta(h) & =\tilde{f}_{v}^{u}\left(t_{h}^{\prime}\right), \\
\Theta(h+1) & =\tilde{t}_{v}\left(t_{h+1}^{\prime}\right)=\tau \Delta(h)+\mathrm{a}(h)+\mathrm{b}(h) .
\end{aligned}
$$

Bu tanımlamalar ışığı altında, $\Delta(\mathrm{h}+1)$ değerini şu şekilde ifade edebiliriz:

$$
\begin{aligned}
\Delta(\mathrm{h}+1) & =\Delta(\mathrm{h})-\alpha \Theta(\mathrm{h}+1) \\
& =\Delta(\mathrm{h})-\alpha(\tau \Delta(\mathrm{h})+\mathrm{a}(\mathrm{h})+\mathrm{b}(\mathrm{h})) \\
& =(1-\alpha \tau) \Delta(\mathrm{h})-\alpha(\mathrm{a}(\mathrm{h})+\mathrm{b}(\mathrm{h})) .
\end{aligned}
$$

$\mathrm{Bu}$ gösterimi kullanarak sistemin evrimini aşağıdaki özyinelemeli matris eşitliği ile gösterebiliriz:

$$
\begin{aligned}
\underbrace{\left[\begin{array}{l}
\Theta(\mathrm{h}+1) \\
\Delta(\mathrm{h}+1)
\end{array}\right]}_{\mathrm{X}(\mathrm{h}+1)} & =\underbrace{\left[\begin{array}{cc}
0 & \tau \\
0 & 1-\alpha \tau
\end{array}\right]}_{\mathrm{A}} \underbrace{\left[\begin{array}{l}
\Theta(\mathrm{h}) \\
\Delta(\mathrm{h})
\end{array}\right]}_{\mathrm{X}(\mathrm{h})} \\
+ & \underbrace{\left[\begin{array}{c}
\mathrm{a}(\mathrm{h})+\mathrm{b}(\mathrm{h}) \\
-\alpha(\mathrm{a}(\mathrm{h})+\mathrm{b}(\mathrm{h}))
\end{array}\right]}_{\mathrm{Y}(\mathrm{h})} .
\end{aligned}
$$

$\mathrm{Bu}$ ifadenin beklenen değerini alacak olursak:

$$
\mathrm{E} \llbracket \mathrm{X}(\mathrm{h}+1) \rrbracket=\mathrm{AE} \llbracket \mathrm{X}(\mathrm{h}) \rrbracket
$$

eşitliği elde edilir. A matrisinin $\lambda_{1}$ ve $\lambda_{2}$ olan özdeğerleri aşağıdaki determinant eşitliği çözülerek $\lambda_{1}=0$ ve $\lambda_{2}=1-\alpha \tau$ şeklinde bulunur. Devingen sistemlerin kararlılık teorisine göre, sistemin asimptotik kararlılı̆̆a erişebilmesi için $\left|\lambda_{1}, \lambda_{2}\right|<1$ sağlanmalı, dolayısıyla

$$
0<\alpha<\frac{1}{\tau}
$$

şartı sağlanmalıdır. Eğer $\alpha$ parametresi yukarıdaki şartı sağlayacak şekilde seçilirse,

$$
\begin{array}{ccc}
\mathrm{E} \llbracket \Delta(\infty) \rrbracket=(1-\alpha \tau) \mathrm{E} \llbracket \Delta(\infty) \rrbracket & \Rightarrow & \mathrm{E} \llbracket \Delta(\infty) \rrbracket=0, \\
\mathrm{E} \llbracket \Theta(\infty) \rrbracket=\tau \mathrm{E} \llbracket \Theta(\infty) \rrbracket & \Rightarrow & \mathrm{E} \llbracket \Theta(\infty) \rrbracket=0,
\end{array}
$$

sağlanacaktır. Dolayısıyla, beklenende tahminleme hatası $\mathrm{E} \llbracket \Theta(\infty) \rrbracket=\tilde{\mathrm{t}}_{\mathrm{v}}(\infty)$ sıfıra yakınsayacaktır. Bir başka deyişle, oransal-integral denetçilerle görev çevrimi uygulandı̆̆ında, ortalamada bütün paketlerin alınma zamanı doğru tahmin edilecek ve paketler zamanında alınacaktır.

Teorem 2: Oransal-integral denetçilerle görev çevrimi uygulandığında, paketlerin alınma zamanı

$$
\gamma=\frac{\alpha^{2}\left(\frac{\varepsilon^{2} \tau}{3}+\sigma_{\mathrm{d}}^{2}\right)}{(2-\alpha \tau)}+\frac{\varepsilon^{2} \tau}{3}+\sigma_{\mathrm{d}}^{2}
$$

asimptotik varyansıla tahmin edilmektedir.

İspat: Tahminleme varyansını bulmak için $\lim _{h \rightarrow \infty} \operatorname{Var}(\Theta(h))$ varyans değeri bulunmalıdır. Zaten $\llbracket \Theta(\infty) \rrbracket=0$ eşitliği bilindiği için, $\operatorname{Var}(\Theta(\infty))=\mathrm{E} \llbracket \Theta(\infty)^{2} \rrbracket$ elde edilir ve hesaplanması gereken değer $E \llbracket \Theta(\infty)^{2} \rrbracket$ değeri olmaktadır. Dolayısıyla, 


$$
\begin{aligned}
\mathrm{E} \llbracket \Theta(\infty)^{2} \rrbracket=\tau^{2} \mathrm{E} \llbracket \Delta(\infty)^{2} \rrbracket & \\
& +\mathrm{E} \llbracket(\mathrm{a}(\mathrm{h})+\mathrm{b}(\mathrm{h}))^{2} \rrbracket .
\end{aligned}
$$

Öncelikle

$$
\mathrm{E} \llbracket \Delta(\infty)^{2} \rrbracket \quad \text { değerini }
$$

hesaplayalım:

$$
\begin{aligned}
\mathrm{E} \llbracket \Delta(\infty)^{2} \rrbracket=(1-\alpha \tau)^{2} \mathrm{E} \llbracket \Delta(\infty)^{2} \rrbracket \\
+\alpha^{2} \mathrm{E} \llbracket(\mathrm{a}(\mathrm{h})+\mathrm{b}(\mathrm{h}))^{2} \rrbracket .
\end{aligned}
$$

$\mathrm{Bu}$ değeri hesaplamak için öncelikle $\mathrm{E} \llbracket(\mathrm{a}(\mathrm{h})+\mathrm{b}(\mathrm{h}))^{2} \rrbracket$ değeri hesaplanmalıdır. $a(h)$ ve $b(h)$ birbirinden bağımsız şans değişkenleri olduğu için

$$
\begin{array}{r}
\mathrm{E} \llbracket(\mathrm{a}(\mathrm{h})+\mathrm{b}(\mathrm{h}))^{2} \rrbracket \\
=\mathrm{E} \llbracket \mathrm{a}(\mathrm{h})^{2} \rrbracket+\mathrm{E} \llbracket \mathrm{b}(\mathrm{h})^{2} \rrbracket
\end{array}
$$

elde edilir. Eğer $t_{h+1}-t_{h} \approx \tau$ varsayarsak, $\quad \mathrm{E} \llbracket \mathrm{a}(\mathrm{h})^{2} \rrbracket=\frac{\varepsilon^{2} \tau}{3} \quad$ ve $\mathrm{E} \llbracket \mathrm{b}(\mathrm{h})^{2} \rrbracket=\sigma_{\mathrm{d}}^{2}$ olduğu için, bu değer basit adımlar sonucunda

$$
\mathrm{E} \llbracket \Delta(\infty)^{2} \rrbracket=\frac{\alpha^{2}\left(\frac{\varepsilon^{2} \tau}{3}+\sigma_{\mathrm{d}}^{2}\right)}{\left(2 \alpha \tau-\alpha^{2} \tau^{2}\right)}
$$

olarak bulunur. Bu değerleri de, ispatın en başında belirttiğimiz $\mathrm{E} \llbracket \Theta(\infty)^{2} \rrbracket$ ifadesinde yerine koyacak olursak, birkaç basit adımdan sonra Teorem 2'deki sonucu elde etmiş oluruz. Görüleceği gibi, asimptotik varyans, saat kararlılığını temsil eden $\varepsilon$ donanımsal parametresine, iletişim sıkılığın ifade eden $\tau$ değerine ve iletişim gecikmelerini ifade eden $\sigma_{\mathrm{d}}^{2}$ değerine bağlıdır. Önerdiğimiz algoritmanın integral kazanımı olan $\alpha$ değeri de başarımı etkileyen önemli bir etkendir.

\section{Paket Alım Penceresinin Büyüklüğü}

Bu bölümde, bir önceki bölümdeki analiz sonuçlarını kullanarak $\mathrm{v}$ düğümünün paket alım penceresinin (Şekil 1'de gösterilen $\mathrm{W}$ değeri) ne kadar büyük olması gerektiğin incelenecektir. v düğümünün $u$ dügümünden $t$ anında gönderilecek bir sonraki paketin alım zamanını $\hat{\mathrm{t}}_{\mathrm{v}}\left(\mathrm{t}^{\prime}\right)$ olarak tahmin ettiğini varsayalım. İletişim süresince meydana gelen gecikmeler, saat sapmaları ve tahminleme hataları yüzünden, v düğ̈̈münün paketi doğru alabilmesi için bir koruma zamanına (guard time) ihtiyacı vardır. Dolayısıyla, v düğümü alıcı-verici donanımını tahminlediği zaman koruma zamanını kullanarak biraz önce açmalıdır.

$\mathrm{v}$ düğümü $\mathrm{u}$ düğümü tarafindan $\mathrm{t}$ anında gönderilen paketi $\hat{\mathrm{t}}_{\mathrm{v}}\left(\mathrm{t}^{\prime}\right)$ anında \%99.7 olasılıkla alabilmek için, kendi alım penceresinin büyüklüğü olan $\mathrm{W}=\mathrm{l}_{\mathrm{pkt}}+$ $l_{\text {guard }}$ ifadesindeki $l_{\text {guard }}$ değerini aşağıdaki gibi

$$
l_{\text {guard }}=3 \sqrt{\gamma}
$$

ayarlamalıdır. Görüleceği gibi, tahminleme hatası, yani $\gamma$ değeri arttıkça, $l_{\text {guard }}$ değeri ve dolayısıyla paket alım penceresi $\mathrm{W}$ büyüyecek, alıcı-verici daha fazla açık kalacak ve daha fazla enerji harcanacaktır. Teorem 2'de gösterdiğimiz oransal-integral denetçiler ile görev çevriminin $\gamma$ varyansı, saatin kristal salınım üretecinin (oscillator) kararlılığını ifade eden $\varepsilon$ değerine, paket alım sıklığı olan $\tau$ değerine ve mesaj gecikmelerindeki belirsizlikleri ifade eden $\sigma_{d}^{2}$ değerine bağlıdır. Dolayısıyla, $v$ düğümü sistemdeki bu parametrelerin değer aralıklarını bilirse, $\gamma$ ve dolayısıyla $l_{\text {guard }}$ değerini hesaplayabilir. Bu sayede kendi paket alım penceresini verimli bir şekilde ayarlayarak paketleri yüksek olasıllkla kaybetmeden alacak ve enerji tüketimini azaltacaktır.

Şekil 5'te değişik iletişim sıklığı ve integral kazanımı değerleri için, MATLAB benzetimleri yardımıyla alım penceresi W değerinin önemli bir kısmını ifade eden $\gamma$ değerindeki değişimi 
gösterilmektedir. Benzetimlerde $\varepsilon=\tau=10$ değeri için, integral kazanımı $0<$ $64 \mathrm{e}-12 \quad$ ve $\sigma_{\mathrm{d}}^{2}=16 \mathrm{e}-8$ olarak $\quad \alpha<\frac{1}{\tau}$ ifadesine göre aralığındaki $(0,0.1)$ seçilmiştir. Şeklin solunda görüleceği arasındaki değerleri alabilmektedir. gibi, $\alpha=1 \mathrm{e}-6$ değeri için, paket alım sıklığının artması algoritmanın daha sık çalıştırılmasını sağlayacak ayrıca daha önce Teorem 2'de gösterdiğimiz varyans değerinin küçülmesini sağlayarak $l_{\text {guard }}$ değerini ve dolayısıyla $W$ değerini küçültecektir. Benzer şekilde, sabit bir

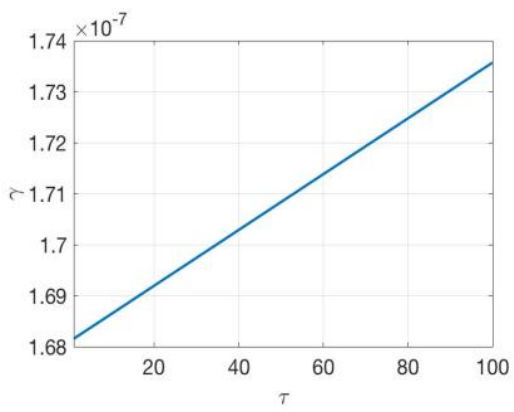
Şeklin sağında gösterildiği gibi, integral kazancının asimptotik varyansı küçülten bir minimum değeri vardır. Ancak, integral kazancının küçük değerlerinin yakınsama süresini uzatacağı unutulmamalıdır.

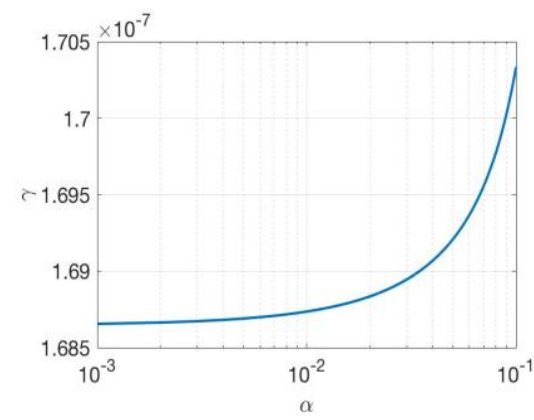

Şekil 5. Paket alım penceresi W'nin haberleşme devri $\tau$ ve integral kazanımı $\alpha$ ile değișimi.

\section{Deneysel Sonuçlar}

$\mathrm{Bu}$ bölümde, önerilen yöntemin uygulamada da geçerli ve tutarlı olduğunu göstermek için, deneysel sonuçlar sunulacaktır. Önerilen yöntem KAA için genel geçer işletim sistemi olan TinyOS 2.1.1 ortamında gerçeklenmiştir. Deneylerde MICAz algılayıcı dügümleri kulanılmıştır. MICAz donanım ortamındaki zamanlayıcılar için $23 \mathrm{KHz}$ kuvars salınıcı kristali saat kaynağı olarak kullanılmıştır. Dolayısıyla düğümler yaklaşık 32 mikrosaniye hassasiyetinde zaman ölçümü yapabilmektedirler.

Deneylerde bir ana (master) düğüm kendi kapsama alanı içerisindeki bir diğer alıcı düğüme periyodik olarak her 30 saniyede bir paket göndermektedir.
Alıcı düğüm paketi aldığında, kendi tahminleme hatasını hesaplamakta ve bu değeri PC'ye bağlı bir merkezi düğüme göndermektedirler. Merkezi düğüm aldığı hata saat değerlerini seri porttan, bu portu dinleyen bir uygulamaya göndermektedir. Uygulama kendisine gelen anlı hata değerlerini saklamaktadır. Deney sonunda, saklanan değerler kullanılarak grafiksel olarak gösterilmektedir.

Deneylerde oransal-integral denetçisi tabanlı yöntemimizin temel parametresi olan $\alpha$ parametresi için değişik değerler seçilerek yöntemin gerçek bir donanım ortamındaki başarımı gözlemlenmiştir. Deney ortamindan toplanan tahminleme hatası Şekil 6'da gösterilmiştir. 

Döngüsü

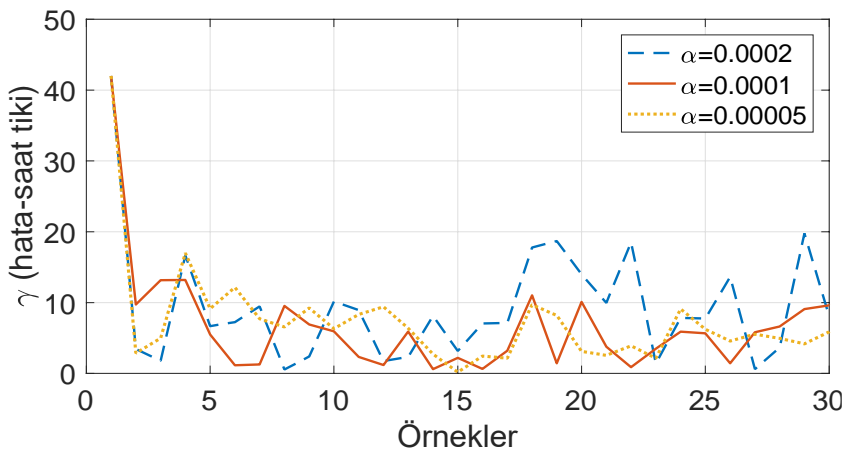

Şekil 6. Alıcı düğümün gönderici dügümün gönderme zamanına ilișkin tahminlerinin hatası.

Şekil 6'da gösterilen değerler göz önüne alındığında, daha büyük bir $\alpha$ değeri olan 0.0002 değeri için gözlemlenen tahminleme hatası değerleri daha büyüktür. Bu durum Șekil 5'te gösterilen benzetim sonuçları ile tutarlıdır: Daha büyük $\alpha$ değerleri daha büyük tahminleme hatasına yol açar. Ancak $\alpha$ için seçilen 0.0001 ve 0.00005 değerleri karşılaştırıldığında, tahminleme hata değerleri oldukça benzerdir. Bu durum şu şekilde açıklanabilir: $32 \mathrm{KHz}$ hızında çalışan saat ile 32 mikrosaniyeden daha hassas ölçüm yapılamamaktadır. Dolayısıla nicemleme hataları (quantization error) nedeniyle, $\alpha$ değerinin belirli bir değerin altına düșmesi tahminleme hatasını değiștirmemektedir. Sonuç olarak $\alpha$ için seçilen 0.0001 önerilen yöntem için uygun bir değerdir ve yaklaşık 3,2 milisaniyelik bir tahminleme hatasına yol açmaktadır.

\section{Sonuç ve Gelecek Calıșmalar}

$\mathrm{Bu}$ makalede, KAA'larda düğümlerin alıcı-vericilerini bir görev döngüsü mekanizması ile kapatıp açarak enerji tüketimlerini azaltmaları konusuna odaklanılmıștır. Güncel literatürde ilk defa, bu tip bir görev döngüsü için oransal-integral denetleyicilerin kullanılması önerilmiștir. Önerilen yöntemin ișlem ve bellek yükü açısından oldukça hafif olduğunun altını çizilerek, matematiksel analizler yardımıyla başarımı analitik olarak gösterilmiştir. Buna ek olarak, MATLAB benzetimleri yardımıla teorik sonuçların doğruluğunu da gösterilmiştir. Önerilen yöntemin gerçek bir KAA ortamında geliștirimi ve deneysel sonuçları da gösterilmiştir. Gelecek çalışması olarak önerilen yöntemin gerçek KAA uygulamalarında kullanılması ve uygulama ihtiyaçları doğrultusunda çok düğümden oluşan bir ağdaki başarımının değerlendirilmesi hedeflenmektedir.

\section{Kaynakça}

[1] Lamport, L., "Time, clocks, and the ordering of events in a distributed system", Communications of the ACM, 21(7), 558-565, 1978.

[2] Lenzen, C., Locher, T., Wattenhofer, R., "Tight bounds for clock synchronization", Journal of the ACM (JACM), 57(2), 8, 2010.

[3] K. S. Yıldırım, Kablosuz Algılayıcı Ağlarında Saat Eşzamanlaması, Ege Üniversitesi, Doktora Tezi, Fen Bilimleri Enstitüsü, 2012.

[4] Burri, N., Von Rickenbach, P., Wattenhofer , R, "Dozer: ultra-low power data gathering in sensor networks", 26th International Symposium on Information 
Processing in Sensor Networks, Cambridge, MA, 2007.

[5] Akyildiz, I. F., Vuran, M. C., Wireless sensor networks, John Wiley \& Sons, 2010.

[6] Guo, S., He, L., Gu, Y., Jiang, B., He, T., "Opportunistic flooding in lowduty-cycle wireless sensor networks with unreliable links", IEEE Transactions on Computers, 63(11), 2787-2802, 2014.

[7] İnternet: Texas Instruments, http://www.ti.com/

[8] Polastre, J., Szewczyk,, R., Culler, D., "Telos: Enabling ultra-low power wireless research," IPSN 2005, Fourth International Symposium on Information Processing in Sensor Networks, Los Angeles, California, USA, April 24 - 27, 2005.

[9] Yıldırım, K. S., Carli, R., Schenato, L., "Adaptive control-based clock synchronization in wireless sensor networks." 2015 European Control Conference (ECC), Linz, pp. 28062811, 2015.

[10] Maróti, M., Kusy, B., Simon, G., Lédeczi, A., "The flooding time synchronization protocol", Proceedings of the 2nd international conference on Embedded networked sensor systems (SenSys '04), ACM, New York, NY, USA, 39-49, 2004

[11] Polastre, J., Hill, J., Culler, D., "Versatile low power media access for wireless sensor networks", Proceedings of the 2nd international conference on Embedded networked sensor systems (SenSys '04), ACM, New York, NY, USA, 95-107.

[12] Ye, W., Heidemann, J., Estrin, D.
"An energy-efficient mac protocol for wireless sensor networks", INFOCOM 2002 Proceedings.Twenty-First Annual Joint Conference of the IEEE Computer and Communications Societies, pp. 1567-1576 vol.3, 2002.

[13] van Hoesel, L., Havinga, P. "A lightweight medium access protocol (lmac) for wireless sensor networks: Reducing preamble transmissions and transceiver state switches," 1st International Workshop on Networked Sensing Systems, INSS 2004, Tokio, Japan, 2004

[14] lae Noh, K., Serpedin, E., Qaraqe, K. "A new approach for time synchronization in wireless sensor networks: Pairwise broadcast synchronization," Wireless Communications, IEEE Transactions on, vol. 7, no. 9, pp. 3318-3322, 2008.

[15] Huang, H., Yun, J., Zhong, Z., Kim, S., He, T., "Psr: Practical synchronous rendezvous in low-duty-cycle wireless networks", 2013 Proceedings IEEE INFOCOM, Turin, pp. 2661-2669, 2013

[16] Ylldırım, K. S., Aantjes, H., Majid, A. Y., Pawełczak, P, "On the Synchronization of Intermittently Powered Wireless Embedded Systems". arXiv preprint arXiv:1606.01719, 2016

[17] A. Leva, F. Terraneo, L. Rinaldi, A. V. Papadopoulos, and M. Maggio, "High-precision low-power wireless nodes' synchronization via decentralized control," IEEE Trans. Control Syst. Technol., vol. 24, no. 4, pp. 1279-1293, Jul. 2016. 
K. S. Yıldırım / Kablosuz Algılayıcı Ağlarında Alıcı-Vericilerin Oransal-İntegral Denetleyiciler ile Görev Döngüsü

[18] R. Carli and S. Zampieri, "Network clock synchronization based on the second-order linear consensus algorithm," IEEE Trans. Autom. Control, vol. 59, no. 2, pp. 409-422, Feb. 2014

[19] R. Lim, B. Maag, and L. Thiele, "Time-of-flight aware time synchronization for wireless embedded systems," in EWSN 2016, pp. 149-158.

[20] C. Lenzen, P. Sommer, and R. Wattenhofer. PulseSync: An efficient and scalable clock synchronization protocol. ACM/IEEE Transactions on Networking (TON), Mar 2014. 